LINGUA, Vol. 14, No. 2, September 2017

p ISSN: 1979 9411; e -ISSN: 2442 238X

Http://lingua.pusatbahasa.or.id; Email:presslingua@gmail.com

Center of Language and Culture Studies, Surakarta, Indonesia

Syah, Aini Nur. 2017. Kajian Stilistika pada Tajuk Rencana

Surat Kabar Harian Umum Haluan. Lingua (2017), 14(2): 243 258.

\title{
KAJIAN STILISTIKA PADA TAJUK RENCANA SURAT KABAR HARIAN UMUM HALUAN
}

\author{
Nur Aini Syah \\ Universitas Sebelas Maret \\ Jl. Ir. Sutami 36A, Surakarta, Indonesia \\ Email: nurainisyah2014@gmail.com
}

\begin{abstract}
This qualitative study analyzes style used in the Haluan newspaper, emphasizing the language used in its editorials. The language styles were focused on the word choice, figurative language, imagery, and the role of the style. The data in this study were a lingual unit in the form of words, phrases, or clauses. The data sources was Editorial posted on June $6^{\text {th }}, 2016$. The results of this study showed that the use of connotative, general, special senses, and a scientific word was prominent. The figurative language, such as climax, anticlimax, repetition, redundancy, enumeration, ellipsis, polidenton, paradoxically, correction, and personification was dominant. The images contained in this Editorial included visual, motion and auditory imageries. Spiritual and social values play a role in the Haluan Daily News Editorial.
\end{abstract}

Keywords: Editorial, Stilistika, Newspapers

Penggunaan bahasa dapat dilakukan baik dalam bentuk lisan maupun tulisan. Bahasa memiliki fungsi sebagai alat komunikasi, yaitu sebagai alat kerjasama diantara pemakainya. Kondisi ini berkaitan dengan kecanggihan dan beragamnya industri media dan komunikasi mulai cetak hinga elektronik yang menyajikan berita dan sensasi. Hal inilah yang memberikan ruang kepada bahasa merealisasikan pikirannya, seperti merealisasikan pikiran melalui berbagai tulisan di surat kabar, seperti berita, tajuk rencana/edoitorial, pojok, artikel, dan sebagainya. Sebagaimana dengan bahasa jurnalistik, setiap media penerbitan pers memiliki gaya bahasa atau ideologi tertentu dalam tiap penyajiannya.

Penggunaan style atau gaya merupakan cara yang khas yang dipergunakan oleh seseorang untuk mengutarakan atau mengungkapkan diri gaya pribadi (Soediro, 2012:35). Dari definisi yang ada dapat disimpulkan bahwa stilistika atau Style adalah teknik pemilihan ungkapan kebahasaan yang dapat mewakili sesuatu yang akan diungkapkan dan sekaligus untuk mencapai efek keindahan. Style dikatakan sebagai cara untuk mengungkapakn ciri khas pribadi, karena setiap orang mempunyai style sendiri dan semua penggunaaan bahasa dalam konteks apapun pada hakikatnya berhubungan style.

Adanya teori stilistika inilah mendorong peneliti untuk melakukan penelitian dengan menggunakan kajian stilistika. Secara umum penelitian menggunakan kajian stilistika lebih banyak menekankan keunikan pemilihan kata dan gaya bahasa yang 
LINGUA, Vol. 14, No. 2, September 2017

p ISSN: 1979 9411; e -ISSN: 2442 238X

Http://lingua.pusatbahasa.or.id; Email:presslingua@gmail.com

Center of Language and Culture Studies, Surakarta, Indonesia

Syah, Aini Nur. 2017. Kajian Stilistika pada Tajuk Rencana

Surat Kabar Harian Umum Haluan. Lingua (2017), 14(2): 243 258.

digunakan seperti yang pernah dilakukan oleh Nurnaningsih (2010) dalam penelitianya yang berjudul Kajian Stilistika Teks Seksual Dalm Serat Centhini. Peneliti lainya Sunarya Kajian Stilistika Serat Wicara Keras R. Ng Yasadipura (2011) dengan mengungkapakn aspek citraan dalam novel tersebut. Kebanyakan dari penelitian sebelunya mengkaji tentang karya sastra yang berupa puisi, novel, ataupun cerpen. Dari sinilah peneliti mempunyai celah penelitian yaitu penelitian stilistika pada tajuk rencana pada surat kabar harian umum haluan.

Tajuk rencana atau editorial di dalam surat kabar merupakan salah satu bentuk penyampaian informasi kepada pembaca. Tajuk rencana atau editorial merupakan tulisan dalam surat kabar yang merupakan pandangan redaksi terhadap peristiwa yang sedang menjadi pembicaraan pada saat surat kabar itu diterbitkan. Dalam tajuk rencana biasanya diungkapkan adanya informasi atau masalah aktual, penegasan pentingnya masalah, opini redaksi tentang masalah tersebut, kritik dan saran atas permasalahan, dan harapan redaksi akan peran serta pembaca. Dengan demikian, dalam hal ini gaya tidak dipahami semata-mata sebagai hiasan, tetapi benar-benar berfungsi untuk mendukung lahirnya makna sebagaimana yang dimaksud oleh penulis, dan yang juga diharapkan oleh pembaca.

Tujuan penelitian ini adalah untuk mendeskripsikan aspek-aspek stilistika (pilihan kata, bahasa figuratif, citraan) yang terdapat di dalam Tajuk Rencana Surat Kabar Harian Umum Haluan, dan untuk menjelaskan peranan aspek-aspek stilistika yang dominan dalam mendukung nila-nilai yang ada di dalam Tajuk Rencana Surat Kabar Harian Umum Haluan.

Penelitian ini diharapkan dapat memberikan kontribusi terhadap perkembangan ilmu bahasa khususnya pada bidang stilistika yang dapat menambah dan memperkaya pemahaman atau referensi baru untuk peneliti pemula dalam memahami kajian stilistika.

Istilah stilistika berasal dari istilah stylistics dalam bahasa Inggris. Istilah stilistika atau stylistics terdiri dari dua kata style dan ics. Stylist adalah pengarang atau pembicara yang baik gaya bahasanya, perancang atau ahli dalam mode. Ics atau ika adalah ilmu, kaji, telaah. Jadi, stilistika adalah ilmu gaya atau ilmu gaya bahasa. Gaya memang selalu dihubungkan dengan pemakaian atau penggunaan bahasa dalam karya sastra. Ini merupakan hakikat stilistika. Ini menyebabkan stilistika merupakan ilmu gabungan atau interdisipliner. Stilistika menggabungkan ilmu linguistik dengan ilmu sastra.

Diksi ialah pilihan kata. Maksudnya, kita memilih kata yang tepat dan selaras untuk menyatakan atau mengungkapkan gagasan sehingga memperoleh efek tertentu. Pilihan kata merupakan satu unsur sangat penting, baik dalam dunia karang-mengarang maupun dalam dunia tutur setiap hari.

Setiap kata memiliki makna tertentu untuk membuat gagasan yang ada dalam benak seseorang. Bahkan makna kata bisa saja "diubah" saat digunakan dalam kalimat yang berbeda. Hal ini mengisyaratkan bahwa makna kata yang sebenarnya akan diketahui saat digunakan dalam kalimat. Lebih dari itu, bisa saja menimbulkan dampak atau reaksi yang berbeda jika digunakan dalam kalimat yang berbeda. Berdasarkan hal 
LINGUA, Vol. 14, No. 2, September 2017

p ISSN: 1979 9411; e -ISSN: 2442 238X

Http://lingua.pusatbahasa.or.id; Email:presslingua@gmail.com

Center of Language and Culture Studies, Surakarta, Indonesia

Syah, Aini Nur. 2017. Kajian Stilistika pada Tajuk Rencana

Surat Kabar Harian Umum Haluan. Lingua (2017), 14(2): 243 258.

itu dapat dikatakan bahwa diksi memegang tema penting sebagai alat untuk mengungkapkan gagasan dengan mengharapkan efek agar sesuai.

Penggunaan bahasa figuratif merupakan teknik pengungkapan bahasa, yang maknanya tidak merujuk pada makna harfiah kata-kata yang mendukungnya, melainkan pada makna yang tersirat (Nurgiyantorro, 2014:215). Jadi bahasa figuratif merupakan gaya yang sengaja memanfaatkan bahasa kias untuk memperoleh keindahan.

Sejalan dengan pendapat di atas, berdasarkan langsung tidaknya makna Keraf membagi gaya bahasa menjadi: (a) gaya bahasa berdasarkan struktur kalimat, dan (b) gaya bahasa berdasarkan langsung tidaknya makna (2010:124-129).

\section{a. Gaya bahasa berdasarkan struktur kalimat}

Gaya bahasa berdasarkan struktur kaliamt adalah bagaimana tempat sebuah aspek kalimat ayng dipentingakn dalam akliamt tersebut. Gaya bahas berdasarkan struktur kaliamt terdiri atas klimaks, antiklimaks, paralelisme, antithesis dan repetisi (Keraf, 2010:124-128).

\section{b. Gaya bahasa berdasarkan langsung tidaknya makna}

Gaya bahasa berdasarkan makna diukur dari alngsung tidaknya makna, apakah acuan yang dipakai masih mempertahanan makna denotatifnya atau sudah ada penyimpangan. Keraf membagi gaya berdasarkan langsung tidaknya makna menjadi 2 yaitu: (1) gaya bahas retoris terdiri dari: (a) aliterasi, (b) asonansi, (c) anastrof, (d) apofasis, (e) apostrof, (f) asindenton, (g) polisidenton, (h) kiamuus,(i) ellipsis, (j) eufimisme, (k) litotes, (k) hysteron, $(\mathrm{m})$ pleonasme, (n) periphrasis, (o) koreksio, (p) hiperbola, (q) paradoks, (r) oksimoron. (2) gaya bahas kiasan terdiri dari: (a) simile, (b) metafora, (c) alegori, (d) personifikasi, (e) alusi, (f) eponym, (g) epitet, (h) sinekdote, (i) metonimia, (j) antonomasia, (k), hipalase, (l) ironi, (m), sinisme, (n) sarkasme (2010:130-142)

Citraan merupakan penggunaan kata-kata dan ungkapan yang mampu membangkitkan tanggapan indra. Citra (image) dancitraan (imagery) menunjuk pada adanyare produksi mental.Citra merupakan gambaran berbagai pengalaman sensoris yang dibangkitkanoleh kata-kata. Abrams; Kenny dalam Nurgiyantoro (2012:276) citraan merupakan kumpulan citra yang dipergunakan untuk menuliskan objek dan kualitas tanggapan indra yang dipergunakan dalam karya sastra, baik dengan deskripsi secara harafiah maupun kias. Citraan merupakan salah satu unsur stile yang penting karena berfungsi mengkonkretkan dan menghidupkan penuturan (Nurgiyantoro, 2014:275-276).

Citraan terkait dengan pancaindra manusia, kelima jenis citraan itu adalah citraan penglihatan (visual), pendengaran (auditoris), gerak (kinestetik), rabaan (taktiltermal) dan penciuman (olfaktori) (Nurgiyantoro, 2014:277).

\section{METODE}

Penelitian ini merupakan penelitian kualitatif karena penelitian ini bersifat diskriptif, penelitian ini bertujuan untuk memahami dan menggambarkan masalah yang di jabarkan dengan kata- kata serta untuk mengungkapkan berbagai informasi kualitatif 
LINGUA, Vol. 14, No. 2, September 2017

p ISSN: 1979 9411; e -ISSN: 2442 238X

Http://lingua.pusatbahasa.or.id; Email:presslingua@gmail.com

Center of Language and Culture Studies, Surakarta, Indonesia

Syah, Aini Nur. 2017. Kajian Stilistika pada Tajuk Rencana

Surat Kabar Harian Umum Haluan. Lingua (2017), 14(2): 243 258.

dengan pendiskripsian yang teliti dan penuh untuk menggambarkan secara cermat sifatsifat suatu hal, keadaan, gejala, atau fenomena-fenomena yang bisa di ungkap, penelitian itu tidak terbatas pada sekedar pengumpulan data melainkan meliputi juga analisis dan interpretasi mengenai data tersebut (Sutopo,2002:8). Pendekatan kualitatif yang sifatnya deskriptif merupakan pendekatan yang memandang bahwa semua hal yang berupa sistem tanda itu penting.

Permasalahan dalam penelitian ini membahas tentang kajian stilistika dalam Tajuk Rencana Surat Kabar Harian Umum Haluan. Fokus permasalahan di dalam penelitian ini adalah meneliti aspek stilistika (pilihan kata, bahas figuratif dan citraan) dalam Tajuk Rencana Surat Kabar Harian Umum Haluan.

Adapun data dalam penelitian ini berupa satuan lingual berupa kata, kalimat, atau klausa yang mengandung kajian stilistika yang ditemukan di dalam sumber data. Sumber data yang akan di teliti dalam penelitian ini adalah Tajuk Rencana Surat Kabar Harian Umum Haluan. Tajuk rencana yang digunakan sebagai sumber data adalah Tajuk Rencana Surat Kabar Harian Umum Haluan tanggal 6 Juni 2016.

Dalam metode pemerolehan data dalam penelitian ini ada dua metode yaitu teknik simak dan teknik catat (Mahsun 2007:92). Metode pemerolehan data yang di gunakan dalam penelitian ini adalah metode simak karena cara yang di gunakan untuk memperoleh data di lakukan dengan menyimak penggunaan bahasa dan juga mencatat data yang diperolehnya.

\section{HASIL DAN BAHASAN}

Adapun hasil analisis pada tajuk rencana surat kabar harian umum haluan dapat dilihat dalam uraian di bawah ini :

\section{Pilihan Kata}

Penggunaan pilihan kata yang berbeda-beda bertujuan agar pesan yang dimaksudkan bisa tersampaiakan dengan benar. Adapun penggunaann pilihan kata yang terdapat dalam tajuk rencana pada surat kabar harian umum haluan adalah sebagai berikut:

\section{a). Kata Konotatif}

Kata konotatif adalah jenis kata yang memiliki makna tambahan atau nilai rasa yang ada pada sebuah kata. Penggunaan kata konotatif seperti dalam kalimat berikut ini:

(1) Hari ini merupakan hari pertama pelaksanaan bulan penuh berkah (005) tersebut (005/TRSK-HUH/PK-konotatif/6 Juni 2016)

Data no (1) di atas menunjukkan kata konotatif. Satuan lingual bulan penuh berkah mempunyai makna bahwasanya bulan ramadhan adalah bulan yang punya keutamaan dibanding bulan lainnya, bulan yang di dalamnya adanya peningkatan kualitas dan kuantitas agamanya.

\section{b). Kata Umum}


LINGUA, Vol. 14, No. 2, September 2017

p ISSN: 1979 9411; e ISSN: 2442 238X

Http://lingua.pusatbahasa.or.id; Email:presslingua@gmail.com

Center of Language and Culture Studies, Surakarta, Indonesia

Syah, Aini Nur. 2017. Kajian Stilistika pada Tajuk Rencana

Surat Kabar Harian Umum Haluan. Lingua (2017), 14(2): 243 258.

Kata umum adalah kata yang memiliki cakapan makna yang lebih luas daripada kata umum. Penggunaan kata umum seperti dalam satuan lingual berikut:

(2) Di luar meningkatnya gairah kembali kepada ajaran-ajaran agama, (042) ternyata, pelaksana anibadah puasa Ramadhan sendiri perlu mendapat banyak evaluasi. (042/TRSK-HUH/PK-Umum/6 Juni 2016)

Data pada nomor (2) di atas termasuk dalam kata umum. Satuan lingual ajara-ajaran agama termasuk kata umum karena di dalam ajaran agama masih banyak cabangcabangnya seperti ajaran untuk bersedekah, ajaran untuk beribadah puasa dan lain sebagainya.

\section{c). Kata Khusus}

Kata khusus mengacu pada sesuatu yang bersifat khusus. Kata khusus terdapat dalam satuan lingual berikut ini:

(3) Jeda mingguan, dalam bentuk pelaksanaan ibadah shalat Jum'at (036) dan ada jeda bulanan dalam bentuk pelaksanaan puasa Ramadhan (038)(036/038 TRSK-HUH/PK-Khusus/6Juni 2016)

Data di atas data nomor (3) termasuk dalam kata khusus karena mengacu pada hal yang bersifat khusus yaitu khusus ibadah sholat jum'at dan puasa ramadhan.

\section{d). Kata Indera}

Kata indera adalah kata - kata yang menggunakan istilah yang menyatakan pengalaman yang diserap oleh panca indera. Kata indera terdapat dalam satuan lingual berikut ini:

(4) Tadarus pun menggema (023) dari berbagai loud speaker yang ada di masjid dan mushalla yang kadangkala karena terlalu bersemangatnya, mengganggu orang yang sedang istirahat.(023/TRSK-HUH/PK-indera/6 Juni 2016)

Satuan lingual di atas menggema termasuk dalam kata indera karena menyatakan pengalaman yang diserap oleh panca indera yakni oleh panca indera pendengaran (telinga).

\section{e). Kata Ilmiah}

Kata ilmiah adalah kata yang bersifat ilmu, secara ilmu pengetahuan memenuhi syarat (kaidah) ilmu pengetahuan. Kata ilmiah dalam tajuk rencana seperti dalam penggalan berikut ini:

(5) Umat Islam tampak lebih religius dengan terjadinya peningkatan kuantitas(011) ataukualitas(012) ibadahnya (011/012/TRSK-HUH/PKilmiah/6 Juni 2016)

(6) 
LINGUA, Vol. 14, No. 2, September 2017

p ISSN: 1979 9411; e -ISSN: 2442 238X

Http://lingua.pusatbahasa.or.id; Email:presslingua@gmail.com

Center of Language and Culture Studies, Surakarta, Indonesia

Syah, Aini Nur. 2017. Kajian Stilistika pada Tajuk Rencana

Surat Kabar Harian Umum Haluan. Lingua (2017), 14(2): 243 258.

Kata ilmiah kuantitas dan kualitas termasuk kata ilmiah karena secra ilmu pengetahuan memenuhi syarat ilmu pengetahuan. Kuantitas mempunyai arti banyaknya benda atau jumlah sesuatu. Sedangkan kualitas mempunyai arti derajat atau taraf atau mutu sesuatu.

Adapun persentase penggunaan dari keseluruhan data pilihan kata yang terdapat pada tajuk rencana surat kabar harian umum haluan adalah:

Tabel 1, Klasifikasi Pilihan Kata

\begin{tabular}{|c|c|c|c|c|}
\hline No & $\begin{array}{l}\text { Jenis - } \\
\text { JenisPilihan Kata }\end{array}$ & Nomor Data & $\begin{array}{l}\text { Jumlah } \\
\text { Data }\end{array}$ & Prosentase \\
\hline 1. & Kata konotatif & $\begin{array}{l}005,008,018,021,022,040,041, \\
044,064\end{array}$ & 9 & $10,11 \%$ \\
\hline 2. & Kata umum & $\begin{array}{l}002,006,009,013,014,015,017, \\
020,024,025,027,029,030,031, \\
033,034,042,045,046,047,048, \\
049,051,059,060,061,062,066, \\
067,068,070,074,075,077,081, \\
082,084,087,088,089\end{array}$ & 40 & $44,94 \%$ \\
\hline 3. & Kata khusus & $\begin{array}{l}\text { 001,003,004,007,016,019,026, } \\
032,035,036,037,038,039,043, \\
050,052,054,055,057,058,063, \\
065,069,071,072,073,076,078, \\
079,080, \\
085\end{array}$ & 31 & $34,83 \%$ \\
\hline 4. & Kata slang & - & & - \\
\hline 5. & Kata indera & 023 & 1 & $1,12 \%$ \\
\hline 6. & Kata ilmiah & $\begin{array}{l}010,011,012,028,053,056,083, \\
086\end{array}$ & 8 & $8,98 \%$ \\
\hline \multicolumn{3}{|r|}{ Jumlah } & & $100 \%$ \\
\hline
\end{tabular}


LINGUA, Vol. 14, No. 2, September 2017

p ISSN: 1979 9411; e -ISSN: 2442 238X

Http://lingua.pusatbahasa.or.id; Email:presslingua@gmail.com

Center of Language and Culture Studies, Surakarta, Indonesia

Syah, Aini Nur. 2017. Kajian Stilistika pada Tajuk Rencana

Surat Kabar Harian Umum Haluan. Lingua (2017), 14(2): 243 258.

\section{Bahasa Figuratif}

Bahasa figuratif terbagi atas gaya bahasa berdasarkan struktur kalimat dan gaya bahasa berdasarkan langsung tidaknya makna

\section{a. Gaya Bahasa Berdasarkan Struktur Kalimat}

Gaya bahasa berdasarkan sttruktur kalimat dilihat dari bagaimana tempat sebuah aspek kalimat yang dipentingkan dalam kalimat tersebut. Adapun penggunaan gaya bahasa berdasarkan struktur kalimat adalah sebagai berikut:

\section{1) Klimaks}

Gaya bahasa klimaks adalah gaya bahasa yang menyebutkan sesuatu secara berturut-turut yang semakin lama intensitasnya semakin meningkat. Penggunaan klimak terdapat dalam kalimat berikut ini:

(7) Suasana kehidupan mulai berubah. Umat Islam tampak lebih religius dengan terjadinya peningkatan kuantitas atau kualitas ibadahnya. Masjid kembali penuh oleh jamaah yang menunaikan shalat Tarawih, pengajian dan buka bersama digelar di mana-mana, di rumah pribadi maupun di berbagai institusi (093). (093/TRSK-HUH/GB-Klimaks/6 Juni 2016)

Data di atas (6) termasuk dalam penggunaan klimaks karena gaya bahasanya semakin meningkat yaitu diawali dengan suasana kehidupan mulai berubah kemudian dilanjutkan denagn umat islam yang lebuh religius dengan peningkatan kualiatas dan kuantitas ibadahnya. Kemudian semakin emningkat lagi denagn adanya penjelasan adanya masjid yang dipenuhi oleh jamaah pengajian dan buka bersama.

\section{2) Antiklimaks}

Penggunaan gaya bahasa antiklimaks bertujuan untuk memberikan penjelasan yang lebih rinci. Antiklimak terdapat dalam satuan lingual berikut ini:

(8) Pendek kata, pada Ramadan, Muslim diingatkan kembali akan pentingnya nilai-nilai keagamaan yang sebelumnya kurang mendapat perhatian karena disibukkan dengan berbagai urusan dunia yang tak ada habis-habisnya. Segala sesuatu perlu jeda, termasuk dalam beribadah. Jeda dalam bentuk harian yang terbagi dalam lima waktu dalam bentuk perintah melaksanakan shalat. Jeda mingguan, dalam bentuk pelaksanaan ibadah shalat Jum'at, dan ada jeda bulanan dalam bentuk pelaksanaan puasa Ramadhan. Jeda dari suatu rutinitas sangat perlu untuk mengambil jarak, untuk melakukan evaluasi diri. Tanpa evaluasi diri, tak akan ada perbaikan karena kita tak tahu 
LINGUA, Vol. 14, No. 2, September 2017

p ISSN: 1979 9411; e -ISSN: 2442 238X

Http://lingua.pusatbahasa.or.id; Email:presslingua@gmail.com

Center of Language and Culture Studies, Surakarta, Indonesia

Syah, Aini Nur. 2017. Kajian Stilistika pada Tajuk Rencana

Surat Kabar Harian Umum Haluan. Lingua (2017), 14(2): 243 258.

apa yang kesalahan atau kekurangan yang kita jalani. (095).(095/TRSKHUH/GB-Antiklimaks/6 Juni 2016)

Penggunaan antiklimaks di atas menjelaskan tentang ramadhan dan nilai - nilai keagaan yang terkandung di dalamnya.

\section{3) Repetisi}

Repetisi adalah pengulangan satuan lingual yang dipentingkan beberapa kali secara berturut-turut. Penggunaan repetisi seperti dalam kutipan berikut ini:

(9) Jeda dari suatu rutinitas sangat perlu untuk mengambil jarak, untuk melakukan evaluasi diri. Tanpa evaluasi diri, (097) tak akan ada perbaikan karena kita tak tahu apa yang kesalahan atau kekurangan yang kita jalani. ).(097/TRSK-HUH/GB-repetisi/6 Juni 2016)

Kutipan di atas menunjukkan penggunaan repetisi untuk pengulangan satuan lingual yang dipentingkan. Dalam hal ini satuan lingual yang dipentingakn adalah evaluasi diri.

Adapun presentase penggunaan bahasa figuratif berdasarkan struktur aklimat adalah sebagai berikut:

Tabel 4.2 Klasifikasi bahasa figuratif (gaya bahasa berdasarkan struktur kalimat)

\begin{tabular}{|l|l|l|l|l|}
\hline No & $\begin{array}{l}\text { Jenis - Jenisbahasfiguratif } \\
\text { (berdasarkanstrukturkalimat) }\end{array}$ & Nomor Data & $\begin{array}{l}\text { Jumlah } \\
\text { Data }\end{array}$ & Prosentase \\
\hline 1. & Klimaks & $092,093,094,101,103$ & 5 & $29,41 \%$ \\
\hline 2. & Antiklimaks & 095,099 & 2 & $11,76 \%$ \\
\hline 3. & Repetisi & $\begin{array}{l}090,091,096,097,098,100, \\
102,104,105,106\end{array}$ & 10 & $13,15 \%$ \\
\hline \multicolumn{2}{|r|}{ Jumlah } & 17 & $100 \%$ \\
\hline
\end{tabular}

\section{b. Gaya bahasa berdasarkan langsung tidaknya makna}

Gaya bahasa berdasarkan makna diukur dari langsung tidaknay makan, apakah acuan yang dipakai masih mempertahankan makna denotatifnya atau sudah ada penyimpangan. Penggunaan gaya bahasa berdasarkan langsung tidaknya makna adalah sebagai berikut:

\section{1). Pleonasme}

Pleonasme adalah gaya bahasa yang memepergunakan kata-kata lebih banyak daripada yang diperlukan untuk menyatakan suatu pikiran atau gagasan. Penggunaan pleonasme seperti dalam kutipan berikut:

(10) Bulan suci Ramadan, bulan yang penuh keutamaan bagi umat Islam kembali datang (107).(107/TRSK-HUH/GB-pleonasme/6 Juni 2016) 
LINGUA, Vol. 14, No. 2, September 2017

p ISSN: 1979 9411; e -ISSN: 2442 238X

Http://lingua.pusatbahasa.or.id; Email:presslingua@gmail.com

Center of Language and Culture Studies, Surakarta, Indonesia

Syah, Aini Nur. 2017. Kajian Stilistika pada Tajuk Rencana

Surat Kabar Harian Umum Haluan. Lingua (2017), 14(2): 243 258.

Data di atas nomor (19) menunjukkan adanya gaya bahasa pleonasme, yaitu mempergunakan kata-kata lebih banyak uttuk menyatakan suatu pikiran atau gagasan. Dalam hal ini satuan lingual Bulan suci Ramadan digunakan untuk menyatakan bulan yang penuh keutamaan untuk menyatakan suatu pikiran atau gagasan.

\section{2) Enumerasio}

Enumerasio adalah Ungkapan penegasan berupa penguraian bagian demi bagian suatu keseluruhan. Penggunaan enumerasio terdapat daalm kutipan berikut ini:

(11) Suasana kehidupan mulai berubah. Umat Islam tampak lebih religius dengan terjadinya peningkatan kuantitas atau kualitas ibadahnya. Masjid kembali penuh oleh jamaah yang menunaikan shalat Tarawih, pengajian dan buka bersama digelar di mana-mana, di rumah pribadi maupun di berbagai institusi.(108) (107/TRSK-HUH/GB-pleonasme/6 Juni 2016)

Satuan lingual di atas nomor (10) menunjukkan gaya bahasa enumerasio yaitu berupa penguraian bagian demi bagian suatu keseluruhan.

\section{3) Elipsis}

Elipsis adalah suatu gaya yang berwujud menghilangakn suatu aspek kalimat yang dengan mudah dapat diisi atau ditafsirkan sendiri oleh pendengarnya. Penggunaan elipsis seperti dalam kutipan berikut:

(12) Umat Islam tampak lebih religius dengan terjadinya peningkatan kuantitas atau kualitas ibadahnya. (109) (109/TRSK-HUH/GB-elipsis/6 Juni 2016)

Data di atas (11) terjadi elipsis menghilangkan suatu aspek kalimat. Dalam hal ini satuan lingual ibadah mengalami elipsis dari ibadah umat islam.

\section{4) Polisidenton}

Polisidenton merupakan gaya bahasa kebalikan dari asidenton. Dimana beberapa kata, frasa, klausa yang berurutan dihubungkan dengan kata sambung. Penggunaan polisidenton terdapat ppada kutipan berikut ini:

(13) Masjid kembali penuh oleh jamaah yang menunaikan shalat Tarawih, pengajian dan buka bersama digelar di mana-mana, di rumah pribadi maupun di berbagai institusi.(110). (110/TRSK-HUH/GB-polisidenton/6 Juni 2016)

Satuan lingual di atas (12) adanya satuan lingual yang dihubungkan denagn kata penghubung dan (konjungsi aditif).

\section{5) Paradoks}


LINGUA, Vol. 14, No. 2, September 2017

p ISSN: 1979 9411; e -ISSN: 2442 238X

Http://lingua.pusatbahasa.or.id; Email:presslingua@gmail.com

Center of Language and Culture Studies, Surakarta, Indonesia

Syah, Aini Nur. 2017. Kajian Stilistika pada Tajuk Rencana

Surat Kabar Harian Umum Haluan. Lingua (2017), 14(2): 243 258.

Paradoks adalah Pengungkapan dengan menyatakan dua hal yang seolah-olah bertentangan, namun sebenarnya keduanya benar.penggunaan paradoks seperti dalam kutipan berikut ini:

(14) Waktu senggang kini bukannya digunakan untuk beribadah, tetapi (114) dihabiskan untuk menonton TV, bermain game, atau sibuk mengobrol di media sosial(114/TRSK-HUH/GB-paradok/6 Juni 2016)

Data di atas menunjukkan adanya gaya bahasa paradoks yaitu adanya pertentangan antara kalimat pertama dengan kaliamt kedua ditandai dengan satuan lingual tetapi.

\section{6) Koreksio}

Koreksio adalah gayabahasa yang berwujud, mula-mula menegaskan sesuatu, tetapi kemudian memperbaikinya. Seperti dalam kutipan berikut ini:

(15) Padahal jika mengingat hikmah puasa untuk menahan diri, seharusnya berbagai konsumsi yang berlebihan tersebut kita kurangi.(117). (117/TRSKHUH/GB-koreksio/6 Juni 2016)

Data diatas (14) menunjukkan penggunaan gaya bahasa koreksio dengan ditandai satuan lingual seharusnyai untuk menyatakan perbaikan.

\section{7) Personifikasi}

Personifikasi adalah gaya bahasa kiasan yang menggambarkan benda - benda mati yang seolah-olah memiliki sifat - sifat kemanusian. Penggunaan personifikasi seperti dalm kutipan berikut ini:

(16) Bulan puasa sekedar menjadi rutinitas dan rehat sejenak, yang kemudian dirayakan dan di besar-besarkan oleh para produsen untuk memanfaatkan moment puasadan lebaran untuk menggenjotpenjualan. (118). (118/TRSKHUH/GB-personifikasi/6 Juni 2016)

Data di atas (15) menunjukkan gaya bahasa personifikasi yaitu yang menggambarkan benda mati seloah-olah memiliki sifat kemanusiana. Momen puasa dan lebaran menggenjot penjualan. Kata menggenjot menggambarkan sifat benda mati seolah - olah memiliki sifat kemanusian.

Adapun presentase penggunaan bahasa figuratif berdasarkan langsung tidaknya makna adalah sebagai berikut:

Tabel 4.3 Klasifikasi bahasa figuratif (gaya bahasa berdasarkan langsung tidaknya makna)

\begin{tabular}{|l|l|l|l|l|}
\hline No & $\begin{array}{l}\text { Jenis - Jenisbahasafiguratif } \\
\text { (berdasarkanlangsungtidaknyamakna) }\end{array}$ & Nomor Data & $\begin{array}{l}\text { Jumlah } \\
\text { Data }\end{array}$ & Prosentase \\
\hline 1. & Pleonasme & 107 & 1 & $8,33 \%$ \\
\hline
\end{tabular}


LINGUA, Vol. 14, No. 2, September 2017

p ISSN: 1979 9411; e -ISSN: 2442 238X

Http://lingua.pusatbahasa.or.id; Email:presslingua@gmail.com

Center of Language and Culture Studies, Surakarta, Indonesia

Syah, Aini Nur. 2017. Kajian Stilistika pada Tajuk Rencana

Surat Kabar Harian Umum Haluan. Lingua (2017), 14(2): 243 258.

\begin{tabular}{|l|l|l|l|l|}
\hline 2. & Enumerasio & 108,112 & 2 & $16,66 \%$ \\
\hline 3. & Elipsis & 109 & 1 & $8,33 \%$ \\
\hline 4. & Polisidenton & $110,111,113$ & 3 & $25 \%$ \\
\hline 5. & Paradoks & $114,115,116$ & 3 & $25 \%$ \\
\hline 6. & Koreksio & 117 & 1 & $8,33 \%$ \\
\hline 7. & Personifikasi Jumlah & 118 & 1 & $8,33 \%$ \\
\hline \multicolumn{2}{|r|}{} & 12 & $100 \%$ \\
\hline
\end{tabular}

\section{Citraan}

\section{a. Citraan Auditif}

Citraan auditif berkaitan denagn pengongkretan objek-objek bunyi baik yang ditunjukan lewat deskripsi verbal atau truan bunyi. Penggunaan citraan auditif seperti dalm kutipan berikut ini:

(17) Tadarus pun menggema (125) dariberbagai loud speaker yang ada di masjid dan mushalla, yang kadang kala karena terlalu bersemangatnya, mengganggu orang yang sedang istirahat. (125/TRSK-HUH/GB-auditif/6 Juni 2016)

Data di atas (16) menunjukkan penggunaan citraan auditif yaitu pengongkretan objek-objek bunyi.

\section{b. Citraan Visual}

Visual adalah pengongkretan objek yang dapat dilihat oleh mata. Penggunaan citraan visual seperti dalm kutipan berikut ini:

(18) Umat Islam tampak lebih religius dengan terjadinya peningkatan kuantitas ataukualitas ibadahnya.(120) . (120/TRSK-HUH/GB-visual/6 Juni 2016)

Data di atas (17) menunjukkan penggunanan citraan visual yaitu pengongkretan objek yang dapat dilihat oleh mata. Yaitu umat islam dilihat adanya kehidupan yang lebih religius.

\section{c. Citraan Gerak}

Citraaan gerak adalah citraan yang terkait dengan pengongketan objek gerak yang dapt dilihat oleh mata. Penggunaan citraan gerak seperti dalm kutipan berikut ini:

(19) Masjid kembalipenuh oleh jamaah yang menunaikan shalat (122) Tarawih, pengajian (123) dan buka bersama (124) digelar di mana-mana, di rumah pribadi maupun di berbagai institusi. (122-5/TRSK-HUH/GBgerak/6 Juni 2016) 
LINGUA, Vol. 14, No. 2, September 2017

p ISSN: 1979 9411; e -ISSN: 2442 238X

Http://lingua.pusatbahasa.or.id; Email:presslingua@gmail.com

Center of Language and Culture Studies, Surakarta, Indonesia

Syah, Aini Nur. 2017. Kajian Stilistika pada Tajuk Rencana

Surat Kabar Harian Umum Haluan. Lingua (2017), 14(2): 243 258.

Adapun presentase penggunaan citraan adalah sebagai berikut:

Tabel 4.4 Klasifikasi Citraan

\begin{tabular}{|c|c|c|c|c|}
\hline No & $\begin{array}{l}\text { Jenis - } \\
\text { JenisPilihan Kata }\end{array}$ & Nomor Data & $\begin{array}{l}\text { Jumlah } \\
\text { Data }\end{array}$ & Prosentase \\
\hline 1. & Citraan visual & $119,120,121,136$ & 4 & $13,33 \%$ \\
\hline 2. & Citraangerak & $\begin{array}{l}122,123,124,126,128,129, \\
130,131,132,133,134,135, \\
137,138,139,140,141,142, \\
143,144,145,146,147,148\end{array}$ & 24 & $60 \%$ \\
\hline 3. & Aitraamauditif & 125,127 & 2 & $6,66 \%$ \\
\hline \multicolumn{3}{|c|}{ Jumlah } & & $100 \%$ \\
\hline
\end{tabular}

\section{Nilai - Nilai di dalam Tajuk Rencana Surat Kabar Harian Umum Haluan}

Nilai-nilai yang ditemukan dalam Tajuk Rencana Surat Kabar Harian Umum Haluan adalah sebagai berikut:

\section{a. Nilai spiritual}

Nilai spiritual adalah nilai yang mengajarkan agar seseorang lebih dekat kepada Tuhan. Nilai spritual yang ada dalam Tajuk Rencana Surat Kabar Harian Umum Haluan adalah sebagai berikut:

\section{1) Religius}

Religius adalah nilai yang mengajarkan ketaatan dan kepatuhan kepada agam yang dianutnya. Sikap religius terdapat dalm kutipan berikut ini:

(20) Umat Islam tampak lebihreligius (150) dengan terjadinya peningkatan kuantitas atau kualitas ibadahnya. (150-5/TRSK-HUH/Nil-spririt religius/6 Juni 2016)

Dari data di atas (19) menunjukkan adanya niali religius dengan dibuktikan adanya meningkatan kualitas atau kuantitas ibadahnya.

\section{2) Evaluasi diri}

Evaluasi diri adalah mengevauasi diri untuk melakukan yang lebih baik lagi. Sikap evaluasi diri terdapat dalm kutipan di bawah ini:

(21) Di luar meningkatnya gairah kembali kepada ajaran-ajaran agama, ternyata, pelaksanaan ibadah puasa Ramadhan sendiri perlu mendapat banyak evaluasi.(153) Dengan alasan puasa, produktifitas karyawan menurun. Masjid dan mushalla dipenuhi dengan para karyawan yang tidur- 
LINGUA, Vol. 14, No. 2, September 2017

p ISSN: 1979 9411; e -ISSN: 2442 238X

Http://lingua.pusatbahasa.or.id; Email:presslingua@gmail.com

Center of Language and Culture Studies, Surakarta, Indonesia

Syah, Aini Nur. 2017. Kajian Stilistika pada Tajuk Rencana

Surat Kabar Harian Umum Haluan. Lingua (2017), 14(2): 243 258.

tiduran karena merasa lapar dan lesu akibat puasa. . (153-5/TRSK-HUH/Nilspririt evaluasi diri/6 Juni 2016)

Dari data di atas (20) nilai spiritual evaluasi diri ditemukan. Hal ini mempunyai arti bahwa buan ramadhan adalh bulan untuk mengevaluasi diri agar menjadi lebih baik disisi tuhan.

\section{3) Menghargai waktu}

Menghargai waktu maksudnya menggunakan waktu sebaik mungkin agar waktu yang ada lebih bermanfaat uuntuk mendekatkan diri pada tuhanya. Penggunaan nilai spiritual mengahrgai waktu ada pada kutipan berikut ini:

(22) Waktu senggang kini bukannya digunakan untuk beribadah, tetapi dihabiskan untuk menonton TV, bermain game, atau sibuk mengobrol di media sosial. Banyak hal bermanfaat yang bisa dilakukan (154). (154/TRSK-HUH/Nil-spriritmenghargai wakt/6 Juni 2016)

\section{b. Nilai sosial}

Nilai sosial adalah nilai yang mengajarkan untuk hidup rukun degan lingkungan sekitar. Adapun nilai sosial yang ada dalam tajuk rencana seperti dalam kutipan berikut ini:

(23) Sikap mereka, termasuk melaksanakan puasa secara sempurna, bisa mendapat hikmah dari puasa diharapkan untuk ikut merasakan rasa lapar dari orang yang tidak mampu. Dengan demikian, dapat meningkatkan empati kepada mereka.(155). (155-/TRSK-HUH/Nil-spririt menghargai wakt/6 Juni 2016)

Data di atas (22) menunjukkan adanya niali sosial dari tajuk rencana harian umum haluan. Hal ini terbukti dengan adanya rasa empati terhadap orang lain yang kurang mampu.

Adapun persentase nilai-nilai dalam tajuk rencana harian umum haluan adalah sebagai berikut:

Tabel 4.5 Klasifikasi Nilai nilai yang ada di dalam tajuk rencana

\begin{tabular}{|l|l|l|l|l|}
\hline No & $\begin{array}{l}\text { Jenis-Jenis nilai yang ada } \\
\text { di dalamtajuk rencana }\end{array}$ & Nomor Data & $\begin{array}{l}\text { Jumlah } \\
\text { Data }\end{array}$ & Prosentase \\
\hline 1. & Spiritual (Religius) & $149,150,151,152$ & 4 & $57,14 \%$ \\
\hline 2. & Spiritual (Evaluasidiri) & 153 & 1 & $14,28 \%$ \\
\hline 3. & $\begin{array}{l}\text { Spiritual } \\
\text { (Menghargaiwaktu) }\end{array}$ & 154 & 1 & $14,28 \%$ \\
\hline 4. & Sosial (empati) & 155 & 1 & $14,28 \%$ \\
\hline Jumlah & 7 & $100 \%$ \\
\hline
\end{tabular}


LINGUA, Vol. 14, No. 2, September 2017

p ISSN: 1979 9411; e -ISSN: 2442 238X

Http://lingua.pusatbahasa.or.id; Email:presslingua@gmail.com

Center of Language and Culture Studies, Surakarta, Indonesia

Syah, Aini Nur. 2017. Kajian Stilistika pada Tajuk Rencana

Surat Kabar Harian Umum Haluan. Lingua (2017), 14(2): 243 258.

\section{SIMPULAN}

Simpulan dari hasil penelitian adalah:

1. Berdasarkan pilihan kata yang ada dalam Tajuk Rencana di Surat Kabar Harian Umum Haluan ditemukan penggunaan data pilihan kata sebanyak 89 data yang meliputi: kata konotatif sebanyak 10,11\%, kata umum sebanyak 44,94\%, kata khusus sebanyak 34,83\%, kata indera sebnayak $1,12 \%$ dan kata kata ilmiah sebanyak 8,98\%. Pilihan kata yang dominan adalah kata umum sebanyak 44,94\%. Kata umum di sini digunakan untuuk menyebutkan sesuatu secara umum yang tidak menunjuk pada orang perorang atau tidak menunjuk perindividu.

2. Penggunaan bahasa figuratif dalam Tajuk Rencana di Surat Kabar Harian Umum Haluan yaitu: klimaks sebanyak 5 data atau 29,41\%, antiklimaks sebanyak 2 data atau $11,76 \%$, repetisi sebanyak 10 data atau $58,82 \%$ pleonasme sebanyak 1 data atau $8,33 \%$, enumerasio sebanyak 2 data atau $16,66 \%$, elipsis sebanyak 1 data atau $8,33 \%$, polisidenton sebanyak 3 data atau $25 \%$, paradoks sebanyak 3 data atau $25 \%$, koreksio sebanyak 1 data atau 8,33\%, dan personifikasi sebanyak 8,33\%. Dari keseluruhan bahasa figuratif yang digunakan, repetisis merupakan gaya bahasa figuratif yang paling banyak digunakan, dengan jumlah penggunaan sebanyak 10 data. Repetisi menjadi dominan untuk menekankan pentingnya sesuatu di dalam tajuk rencana harian umum haluan.

3. Citraan yang terdapat dalam Tajuk Rencana di Surat Kabar Harian Umum Haluan adalah citraan visual sebanyak 4 data atau $13,33 \%$, citraan gerak sebanyak 24 data atau $60 \%$, dan citraan auditif sebanyak 2 data atau 6,66\%. Citraan yang paling dominan adalah citraan gerak yang membantu tersampainya pesan yang ada di dalam tajuk rencana tersebut.

4. Aspek-aspek yang dominan juga berperan terhadap nilai-nilai yang ditemukan dalam Tajuk Rencana di Surat Kabar Harian Umum Haluan yaitu, nilai spritual, dan nilai sosial. Aspek stilistika yang dominan yang pertama adalah pilihan kata umum yang berperan terhadap nilai yang ditemukan terutama nilai spiritual. Aspek dominan selanjutnya yaitu repetisi yang berperan terhadap nilai-nilai yang ada tterutama nilai spiritual untuk menekankan nilai spiritual (keagamaan). Aspek dominan terakhir adalah citraan gerak yang berperan terhadap nilai-nilai yang ada terutama nilai sosial dan juga nilai spiritual (keagamaan).

\section{DAFTAR PUSTAKA}

Alwi, Hasan (Ed). 2001. Bahan Penyuluhan Bahasa Indonesia: Paragraf. Jakarta: Depdiknas.

Badudu, J.S, 1975. Sari Kesusastraan Indonesia. Bandung: CV Pustaka Prima

Keraf, groys. 2008. Diksi dan Gaya Bahasa. Jakarta: PT. Gramedia Pustaka Utama

Keraf, Gorys. 1983. Komposisi. Flores: Nusa Indah.

Ratna, Nyoman Kutha.2008. Stilistika Kajian Puitika Bahasa, Sastra dan Budaya. Yogyakarta: Pustaka Pelajar

Moeliono, M. Anton. 1989. Kembara Bahasa: Kumpulan Karangan Tersebar. Jakarta: Gramedia. 
LINGUA, Vol. 14, No. 2, September 2017

p ISSN: 1979 9411; e -ISSN: 2442 238X

Http://lingua.pusatbahasa.or.id; Email:presslingua@gmail.com

Center of Language and Culture Studies, Surakarta, Indonesia

Syah, Aini Nur. 2017. Kajian Stilistika pada Tajuk Rencana

Surat Kabar Harian Umum Haluan. Lingua (2017), 14(2): 243 258.

Nurgiantoro, Burhan.2014. Stilistika. Yogyakarta: Gadjah Mada University Press

Pusat Pembinaan dan Pengembangan Bahasa. 2007. Pedoman Umum Ejaan Bahasa

Indonesia yang Disempurnakan. Tera, Yogyakarta.

Soediro, Satoto. 2012.Stilistika. Yogyakarta: Penertbit Ombak

Tarigan, Hendry Guntur. 1985. Pengajaran Bahasa. Bandung: Angkasa. 
LINGUA, Vol. 14, No. 2, September 2017

p ISSN: 1979 9411; e -ISSN: 2442 238X

Http://lingua.pusatbahasa.or.id; Email:presslingua@gmail.com

Center of Language and Culture Studies, Surakarta, Indonesia

Syah, Aini Nur. 2017. Kajian Stilistika pada Tajuk Rencana

Surat Kabar Harian Umum Haluan. Lingua (2017), 14(2): 243 258. 